\title{
As políticas públicas da educação brasileira e seus reflexos no ensino aprendizagem do ensino médio.
}

The public policies of brazilian education and its reflexes in high school learning.

\author{
Angélica D. Medeiros Junqueira \\ Escola Municipal Guiomar de Campos Miranda (Brasil) \\ angelica_mjunqueira@hotmail.com
}

Fecha recepción: 14/10/2019

Páginas 16-25

Fecha aceptación: 25/11/2019

\section{Resumo.}

O presente artigo é resultado de uma pesquisa bibliográfica realizada no contexto de uma investigação que pretende analisar e refletir sobre as políticas públicas brasileiras destinada ao ensino médio e seu reflexo no ensino aprendizagem dos alunos desta fase, trabalhou-se com os conceitos de política pública, ensino médio e o ensino aprendizagem objetivando contextualizá-las, já que estão interligadas em um contexto social, educacional e político bem demarcados. Diante disso, este artigo se justifica pela compreensão detalhada das políticas públicas destinada ao Ensino Médio brasileiro, a qual trazem em seu contexto os desafios, avanços e as conquistas já alcançadas, bem como aquelas que ainda serão colocadas em prática, e o reflexos destas políticas na aprendizagem dos alunos do Ensino Médio.

Palavras Chaves: ensino médio; políticas públicas; aprendizagem; contexto social

\begin{abstract}
.
This article, the result of a bibliographical research carried out in the context of an investigation that aims to analyze and reflect on Brazilian public policies aimed at high school and its reflection on the teaching and learning of students of this phase, worked with the concepts of public policy, high school and teaching learning aiming to contextualize them, since they are interconnected in a well demarcated social, educational and political context. Given this, this article is justified by the detailed understanding of public policies for the Brazilian High School, which bring in its context the challenges, advances and achievements already achieved, as well as those that will still be put into practice, and the reflexes of these policies. in the learning of high school students.
\end{abstract}

Keywords: high school; public policy; learning; social context 


\section{1.-Introdução.}

O objetivo deste artigo é analisar e refletir sobre as políticas públicas brasileiras destinada para o ensino médio, considerando que a aprendizagem do aluno no ensino médio tem como finalidade a preparação do aluno para o trabalho e para o exercício da cidadania. Assim, trabalhou-se com os conceitos de política pública, ensino médio e a aprendizagem objetivando contextualizá-las, já que estão interligadas em um contexto social, educacional e político bem definido. 0 artigo realizado deu-se por meio de pesquisa bibliográfica que segundo Gil (2002), é desenvolvido com base em material já elaborado, constituído especificamente de livros e artigos científicos. Sendo relevante apreciar a opinião de Lakatos e Marconi (2010), onde recomendam que "[...] a pesquisa bibliográfica não é mera repetição do que já foi dito ou escrito sobre certo assunto, mas propicia o exame de um tema sob novo enfoque ou abordagem, chegando a conclusões inovadoras".

Recentemente, mais uma vez fez-se presente uma tentativa de reformar o ensino brasileiro, e o foco da vez é o ensino médio. A alegação de quem propõe a reforma é de que está se buscando retirar a obrigatoriedade de alguns conteúdos desinteressantes aos alunos e permitir-lhes que optem por áreas com que se identificam para que possam aprofundar os estudos nessas áreas, concomitantemente à ideia é incluir formação técnica, proporcionando ao estudante do ensino médio ao mesmo tempo à conclusão dessa etapa possa obter formação técnica que lhe permita maior facilidade para ingressar no mercado de trabalho. As alterações provocadas pelo novo modelo do Ensino Médio trazem modificações bastante significativas na estrutura do ensino nacional.

Diante disso, este artigo se justifica pela compreensão detalhada das políticas públicas na educação brasileira, a qual trazem em seu contexto os desafios, avanços e as conquistas já alcançadas, bem como aquelas que ainda serão colocadas em prática, e o reflexos destas políticas na aprendizagem dos alunos do Ensino Médio.

\section{2.-Políticas Públicas.}

$O$ desenvolvimento de ações e programas do atual governo federal e a reorganização do MEC configuram um cenário de possibilidades, que precisam ser consideradas para uma efetiva política pública nacional para o Ensino Médio comprometida com as múltiplas necessidades sociais e culturais da população brasileira. Política pública são ações sociais coletivas que têm por objetivo à garantia de direitos perante a sociedade, envolvendo compromissos e tomadas de decisões para determinadas finalidades. É importante saber como são definidas algumas atividades que requerem uma avaliação nas etapas de planejamento das políticas e instruções governamentais, que geram informações que possibilitam novas escolhas na análise para possíveis necessidades de reorientações de ações para se alcançar os objetivos traçados.

A sociedade é dinâmica e, por isso, a compreensão da função do Estado e das necessidades educacionais também muda ao longo dos anos. As políticas públicas de educação geralmente estão associadas aos momentos históricos de um país e do mundo e à interpretação de poder de cada época. 
No Brasil, elas são estabelecidas por um processo pedagógico nacional, no qual são discutidas as temáticas necessárias para garantir uma educação de qualidade, e apoiadas pela legislação. Exigem, ainda, a participação da sociedade como um todo educadores, alunos, pais e governo.

Normalmente, as políticas educacionais têm origem nas leis votadas pelo Poder Legislativo nas esferas federal, estadual e municipal, embora membros do Poder Executivo também possam propor ações nessa área. Aos cidadãos cabe participar dos conselhos de políticas públicas, que são espaços de discussão de demandas.

Dessa forma, as políticas educacionais podem ser entendidas como um meio de construção de valores e conhecimentos que possibilitam o pleno desenvolvimento do educando, incluindo sua capacidade de se comunicar, compreender o mundo ao seu redor, defender suas ideias e exercer a cidadania.

Ao estabelecer modelos educacionais concebidos pelos cidadãos e pelo governo, essas políticas públicas viabilizam a criação de uma sociedade apta para trabalhar, questionar e contribuir com o crescimento da nação - por isso, são de extrema importância para o país.

Na década de 1990, com a aprovação da Lei n. 9.394/96, o ensino secundário recebeu a denominação de ensino médio, não obrigatório, destinado aos jovens de 15 a 17 anos egressos do ensino fundamental, a partir de 1997, a chamada reforma do ensino médio e da educação profissional determina que o ensino técnico seja ofertado de forma complementar, paralela ou sequencial e separado do ensino médio regular. A condição de modalidade conferida à educação profissional na Lei n. 9.394/96, com possibilidade de articular-se com as etapas e níveis do ensino regular sem deles ser parte integrante, confere-lhe um caráter secundário, que também se estende ao financiamento, à gestão Políticas para o ensino médio no Brasil: perspectivas para a universalização.

A Lei de Diretrizes e Bases da Educação Brasileira (Lei n 9.394, de 1996) configura a identidade do Ensino Médio como uma etapa de consolidação da educação básica, de aprimoramento do educando como pessoa humana, de aprofundamento dos conhecimentos adquiridos no ensino fundamental, para continuar aprendendo, e de preparação básica para o trabalho e a cidadania. Também possibilitou a integração com a profissionalização, de forma ambígua, no capítulo da educação básica e em um capítulo próprio, na qual a "A educação profissional e tecnológica, no cumprimento dos objetivos da educação nacional, integra--se aos diferentes níveis e modalidades de educação e às dimensões do trabalho, da ciência e da tecnologia" (Redação dada pela Lei 11.741, de 2008).

A organização curricular do ensino médio é, então, destacada no Art. 36 da LDBEN/1996, especificamente no parágrafo $1^{\circ}$, quando nele são instituídas as competências que os alunos, ao término dessa etapa, devem demonstrar:

Art. $36, \S 1^{\circ}$ - Os conteúdos, as metodologias e as formas de avaliação serão organizados de tal forma que ao final do ensino médio o educando demonstre:

I - Domínio dos princípios científicos e tecnológicos que presidem a produção moderna;

II - Conhecimento das formas contemporâneas de linguagem;

III - Domínio dos conhecimentos de Filosofia e de Sociologia necessários ao exercício da cidadania. (Brasil, 2006, p. 26) 
Assim, visando melhor atender a esse aprendizado, os PCNEM (Brasil, 1999) estabeleceram a divisão de conhecimentos escolares em três áreas: Linguagens, Códigos e suas Tecnologias; Ciências da Natureza, Matemática e suas Tecnologias e Ciências Humanas e suas Tecnologias. De acordo esses Parâmetros, tal divisão é justificada porque se observa que os conhecimentos apresentam-se, cada vez mais, imbricados aos conhecedores, quer se encontrem na esfera técnico-científica, quer se situem no cotidiano da vida social.

Então surge, em 2000 o Programa de Melhoria e Expansão do Ensino Médio e 0 Projeto Escola Jovem. Ambos, contando com financiamento do Banco Interamericano de Desenvolvimento, tinham como objetivo apoiar a implementação da reforma curricular e estrutural e a expansão do atendimento no ensino médio no país pelas Unidades Federadas, com vistas à melhoria de sua qualidade e à ampliação de seu grau de cobertura, como modo de garantir maior equidade social (Brasil, 2000).

No período de 2004 a 2007, o Decreto n. 5.154/04 readmitiu ao conjunto das escolas médias no país a possibilidade de integrar o ensino médio à educação profissional. Porém, essa integração ficou a critério das escolas, dos sistemas e das redes de ensino, o que trouxe implicações. Na prática, as experiências foram limitadas em termos qualitativos e quantitativos. Nas redes estaduais de ensino, a oferta da educação profissional é secundarizada em razão da prioridade que a legislação nacional the atribui.

Com efeito, a partir de 2005, inicia-se o processo de institucionalização das Políticas para a Juventude no Brasil, cuja discussão havia sido iniciada em 2003.

Nesse processo, destacam-se a criação da Secretaria e do Conselho Nacional de Juventude (2005); do Programa Nacional de Inclusão de Jovens: Educação, Qualificação e Ação Comunitária (PROJOVEM) (2006); do Programa Universidade para Todos (PROUNI) (2005); do Programa de Apoio a Planos de Reestruturação e Expansão das Universidades Federais (REUNI) (2007); os Pontos de Cultura e as Praças da Juventude, entre outros que, apesar de não serem exclusivos de juventude, atendem, mormente, os jovens brasileiros pertencentes às camadas populares, em situação de defasagem escolar, desemprego e vulnerabilidade social. Diante desse cenário, o MEC lançou o Projeto Ensino Médio Inovador (2009), programa que busca apoiar as Secretarias de Educação dos Estados e do Distrito Federal no desenvolvimento de ações de melhoria do ensino médio. Ênfase é dada à necessidade de mudanças no currículo desse nível de ensino, a um novo sistema de avaliação - 0 novo Enem - e à ampliação do tempo de permanência na escola. Também estão inseridos no programa projetos que promovam a educação científica e humanística, a valorização da leitura, o aprimoramento da relação teoria e prática, a utilização de novas tecnologias e o desenvolvimento de metodologias criativas e emancipadoras.

Para o futuro, vislumbram-se novas expectativas depositadas, sobretudo, no novo Plano Nacional de Educação (PNE) para o período de 2011-2020. O Projeto de Lei que apresenta a proposta de PNE, em tramitação na Câmara dos Deputados, contém como uma de suas metas "Universalizar, até 2016, o atendimento escolar para toda a população de 15 a 17 anos e elevar, até 2020 , a taxa líquida de matrículas no ensino médio para $85 / \%$, nessa faixa etária". 


\section{3.-Ensino Médio.}

O Ensino Médio é um nível de ensino da Educação Básica e é chamado desta maneira por estar entre o os níveis de Ensino Fundamental I e o Superior. Esta denominação sofreu diversas variações ao longo das políticas públicas da educação brasileira. $\mathrm{Na}$ Lei 4.024/61, cuja denominação era Educação de Grau Médio ou Ensino Médio e possuía divisão em dois ciclos: ginasial e colegial.

A partir da reforma de 1971, sob a égide da Lei 5.692, as escolas foram obrigadas a priorizar a formação técnica sobre qualquer outra e seu nome passou a ser Ensino de $2^{\circ}$ Grau e assim se manteve até a publicação da Lei de Diretrizes e Bases (LDB) $n^{0}$ 9.394/96. O mais curioso desta reforma é que ela resultou num ruidoso fracasso, pois tanto não formou técnicos qualificados para o mundo do trabalho, como também não desenvolveu o gosto pela cultura geral na juventude brasileira.

No cenário educacional atual, segundo a LDB n 9.394/96, a denominação deste nível de Ensino passou a ser Ensino Médio. Propôs-se neste nível, no Ensino Médio, estabelecido na Lei de Diretrizes e Bases da Educação Nacional n 9394/96, em seu Art. 35, que o Ensino Médio, compreende a etapa final da educação básica, com duração mínima de três anos e tem como finalidades que vão desde preparar 0 educando para prosseguir os estudos em nível técnico ou superior como também oferecer a preparação básica para o trabalho e para a cidadania, formação ética, desenvolvimento da autonomia intelectual, pensamento crítico e compreensão dos fundamentos científico-tecnológicos dos processos produtivos; compreendendo um currículo que aborde a educação tecnológica básica, a compreensão do significado da ciência, das letras e das artes, assim como, o processo histórico de transformação da sociedade e da cultura; a língua portuguesa como instrumento de comunicação, acesso ao conhecimento e exercício da cidadania.

O Ensino Médio também poderá formar o educando para o exercício de profissões técnicas, sendo este item facultativo. (BRASIL, 1996) Em suma, ao término do Ensino Médio, segundo a LDB n 9.394/96, de modo geral, o aluno deverá ser capaz de possuir domínio dos princípios científicos e tecnológicos que presidem a produção moderna; conhecimento das formas contemporâneas de linguagem; e domínio dos conhecimentos de Filosofia e de Sociologia necessários ao exercício da cidadania.

Ao tratar especificamente sobre o ensino médio, a LDBEN/1998, (Brasil,2006) em seu artigo 35, estabelece que esse nível de ensino se caracteriza por ser a etapa final da educação básica e que deverá ter uma duração de, no mínimo, três anos, tendo por finalidades:

I - A consolidação e o aprofundamento dos conhecimentos adquiridos no ensino fundamental, possibilitando o prosseguimento de estudos;

II - A preparação básica para o trabalho e a cidadania do educando, para continuar aprendendo, de modo a ser capaz de se adaptar com flexibilidade a novas condições de ocupação ou aperfeiçoamento posteriores;

III - O aprimoramento do educando como pessoa humana, incluindo a formação ética e o desenvolvimento da autonomia intelectual e do pensamento crítico;

IV - A compreensão dos fundamentos científico-tecnológicos dos processos produtivos, relacionando a teoria com a prática, no ensino de cada disciplina. (Id. Ibid., p. 28-29). 
Sendo o ensino médio, conforme as três finalidades citadas acima, considerado a etapa final da educação básica, podemos entender seus estudos como o período de concretização e aprofundamento de muitos dos conhecimentos adquiridos ao longo do ensino fundamental. De acordo com os PCNEM (Brasil,1999), com essas finalidades, espera-se dessa etapa de formação o desenvolvimento de competências que permitam ao aluno:

a) A formação da pessoa, de maneira a desenvolver valores e competências necessárias à integração de seu próprio projeto da sociedade em que se situa;

b) $O$ aprimoramento do educando como pessoa humana, incluindo a formação ética e o desenvolvimento da autonomia intelectual e do pensamento crítico;

c) A preparação e orientação básica para a sua integração ao mundo do trabalho, comas competências que garantem seu aprimoramento profissional e permitam acompanhar as mudanças que caracterizam a produção no nosso tempo;

d) $O$ desenvolvimento das competências para continuar aprendendo, de forma autônoma e crítica, em níveis mais complexos de estudos. (Id. Ibid., p.22)

Nesse sentido, o ensino médio, implantado para substituir o até então $2^{\circ} \mathrm{grau}$, deve atuar de maneira que garanta ao aluno a preparação básica para continuação dos seus estudos, a fim de que ele seja inserido no mundo do trabalho, bem como no exercício cotidiano da cidadania, considerando as necessidades político-sociais de sua época.

Os Parâmetros Curriculares para o Ensino Médio - PCNEM (Brasil, 1999) enfatizam que para tudo isso existe[...] a necessidade de se romper com modelos tradicionais, para que se alcancem os objetivos propostos para o Ensino Médio.

A perspectiva é uma aprendizagem permanente, de uma formação continuada, considerando como elemento central dessa formação a construção da cidadania em função dos processos sociais que se modificam.

Alteram-se, portanto, os objetivos da formação do ensino médio. Prioriza-se a formação ética e o desenvolvimento da autonomia intelectual do pensamento crítico. Não há o que se justifique memorizar conhecimento que estão sendo superados ou cujo acesso é facilitado pela moderna tecnologia. O que se deseja é que os estudos desenvolvam competências básicas que lhes permitam desenvolver a capacidade de continuar aprendendo.

De acordo, ainda, com os PCNEM (Brasil), o currículo, enquanto ferramenta da cidadania democrática, deve contemplar conteúdos e estratégias de aprendizagem que preparem o sujeito para a efetivação de atividades "nos três domínios da ação humana: a vida em sociedade, a atividade produtiva e a experiência subjetiva". Essa preparação objetiva integrar "homens e mulheres no tríplice universo das relações políticas, do trabalho e da simbolização subjetiva".

Entende-se que cabe ao ensino médio, enquanto principal política pública para as juventudes, a oferta de espaços e tempos que deem aos jovens oportunidades reais de vivência plena nessa fase da vida. $E$ mais, oportunizem o desenvolvimento da autonomia que permita perceber, criticar e buscar meios para emancipar-se dos processos de dominação capitalista, bem como elaborar outra concepção de sociedade. Compreende-se, ainda, que o caminho é o de investimento real, por parte do poder público constituído, na formação integral dos sujeitos. O que exige, de antemão, reconhecer o direito de cada jovem de refletir e deliberar sobre a sua 
trajetória formativa individual e, então, proporcionar experiências significativas de formação intelectual e cultural.

\section{4.-Ensino Aprendizagem.}

O ensino é uma atividade humana, um trabalho baseado em interações entre pessoas e por isso complexo e desafiador. No entanto, sabe-se que envolver os alunos em suas aprendizagens e administrar a progressão das aprendizagens não é tarefa fácil, porque exige persistência e entusiasmos, pois o êxito da aprendizagem é o objetivo das políticas públicas voltadas para o ensino médio no Brasil, para tanto deve-se analisar o processo ensino-aprendizagem por partes, no intuito de uma melhor compreensão e eficácia.

0 que se estabelece como ensino aprendizagem, diz respeito ao que é possível apropriar-se mentalmente do conceito, a partir do contato com os sentidos; sendo a faculdade básica do conhecimento a inteligência, sendo o movimento da comunicação, que por meio da inteligência desenvolve a capacidade de aprendizagem. Esta, por sua vez, vai desenvolvendo-se por meio da reflexão, do deparar-se com o objeto a ser investigado.

Assim, desenvolve-se o encadeamento de ideias a serem analisadas, investigadas, discutidas, que auxilia no aprimoramento dos conhecimentos adquiridos pelos alunos do ensino médio.

Porém anteriormente acreditava-se que ensinar era transmitir informações hoje "ensinar é desencadear um programa de interações com um grupo de alunos, a fim de atingir determinados objetivos educativos relativos à aprendizagem de conhecimentos e à socialização" (Tardif, 2002).

Segundo Catania (1999) a aprendizagem deve acompanhar a evolução social e 0 contexto em que os alunos encontram-se inseridos, destaca ainda que as propriedades da aprendizagem são paralelas às da evolução tendo em vista que toda estrutura educacional está organizada com o intuito de, primeiramente, promover a aprendizagem e o desenvolvimento do ser humano. Dessa forma, a busca pela aprendizagem deve ser estabelecida em alguns tipos de contingências, sendo assim é necessário observar o saber como, relacionado ao conceito operacional, o saber sobre (análise das instituições de ensino e o contexto atual).

Moreira (2003) explica que a aprendizagem significativa é aquela que ocorre com significado, quando está inserida em conceitos, ideias, proposições, modelos e fórmulas, que estimulam algo novo ao aprendiz e diante disso, aponta que o ensino deve buscar sempre a facilitação da aprendizagem, utilizando o princípio da interação e do questionamento para que o aluno aprenda de maneira significativa.

As aprendizagens repousam dessa forma sobre um tripé: quem aprende, o que se aprende e o outro, ou seja, repousa sobre o sujeito, o objeto, o social.

Outra teoria de aprendizagem é o da esfera que comporta a problemática dos significados, dos valores, do sentido da vida, estes valores são significados e constituídos pelo âmbito cultural dos grupos (Fernandez, 2001).

Já Freire (2006) destaca que a escola deve propiciar educação de base com qualidade, que alargue e potencialize as capacidades dos alunos, para isso é necessário desenvolver o uso dos processos internos, biológicos e sociais. A compreensão e a 
criatividade devem ser buscadas pela escola e pelo educador, visando assim estimular o conhecimento transferido. É imprescindível que o aluno possa agir com autonomia, ou seja, sujeitos próprios corresponsáveis pelas suas aprendizagens e susceptíveis às transformações.

Hoje, o que mais interessa é a aquisição de uma mentalidade científica, o desenvolvimento das capacidades de transformar os conhecimentos em ferramentas de superação dos desafios do cotidiano.

Os métodos devem ser: dinâmicos, inovadores, variados e que leve o aluno a aprender fazendo, e que esteja de acordo com sua realidade. Pois isso proporciona a quem aprende diferentes formas de ver e refletir sobre sua importância no mundo atual, através da investigação dos fatos que pertencem ao seu meio. Dessa forma, pode-se colocar que a aprendizagem humana é determinada pela interação entre o indivíduo e o meio em que participam os aspectos biológicos, psicológicos e sociais.

Nesse contexto é pertinente concluir que é fundamental que o aluno seja instigado em sua criatividade e que suas curiosidades sejam satisfeitas por meio de descobertas concretas, desenvolvendo a sua autoestima, criando em si uma maior segurança e confiança, tão necessárias à vida adulta.

Portanto a eficácia do processo de ensino-aprendizagem está na resposta em que este dá à apropriação do conhecimentos, ao desenvolvimento intelectual e físico do estudante, à formação de sentimentos, qualidades e valores, que alcancem os objetivos gerais e específicos propostos em cada nível de ensino de diferentes instituições, conduzindo a uma posição transformadora, que promova as ações coletivas, a solidariedade e o viver em comunidade.

O objetivo da educação escolar é a aprendizagem do aluno, que acontece através de um processo de interação dinâmica e sucessiva entre aluno e professor, em que 0 questionamento, a investigação e a análise de evidências levam o aluno a realizar descobertas acerca da realidade, construindo seu conhecimento. A aprendizagem que se deseja, deve estar pautada na lógica, para a construção de uma sociedade sadia, uma conscientização democrática com formação para a cidadania.

Na reforma proposta para o ensino médio o ensino aprendizagem traz a interação, que gera aprendizagem que ocorre em um determinado espaço social, em um tempo histórico e em um contexto cultural, cuja dinâmica incorpora mudanças e avanços produzidos pelas diversas ciências, passando por permanente atualização, tendo 0 aluno como sujeito da aprendizagem, porem ele não está sozinho nessa tarefa. Sua aprendizagem é mediada pelo professor. Cabendo ao professor, com sua experiência, propor desafios, problematizações, hipóteses e investigações, levando 0 aluno a mobilizar recursos cognitivos que o levem a progredir em suas descobertas.

Cabendo ao aluno o esforço intelectual, a explicitação de suas hipóteses e de seu raciocínio, assim como a tomada de consciência de suas maneiras de aprender. Dessa forma, a aprendizagem do aluno é um processo reflexivo, de construção de sentidos e de significados na sua relação com os objetos do conhecimento, mediado pelo professor. Cabe aos dois reconhecer que todo conhecimento nunca se torna completo e acabado, o que os estimula permanentemente a buscar saber mais e melhor. 


\section{5.-Conclusão.}

Este estudo foi elaborado tendo em vista a preocupação de analisar em que medida o Ensino Médio, tem sido tratado nas políticas públicas do Brasil. Já que a recente reforma do Ensino Médio pós-LDBEN/1996 (inclusão na Educação Básica, extensão do bolsa-família, livro didático, merenda e transporte escolar) tem se mostrado como possibilidade de melhorar os índices de acesso, permanência e desempenho, além de buscar criar uma identidade para esta etapa de formação.

No Ensino Médio, o ensino aprendizagem é o eixo norteador das metodologias as quais devem ser: dinâmicas, inovadoras, variadas e que leve 0 aluno a aprender fazendo, e que esteja de acordo com sua realidade. Pois isso proporciona a quem aprende diferentes formas de ver e refletir sobre sua importância no mundo atual, através da investigação dos fatos que pertencem ao seu meio.

O Programa Ensino Médio Inovador pode possibilitar o estabelecimento de uma outra centralidade e a valorização do desenvolvimento curricular nas políticas públicas.

Significa uma retomada da concepção do trabalho como princípio educativo não só na forma do ensino médio integrado à educação profissional técnica de nível médio, mas para todo e qualquer ensino médio que pretende garantir uma formação humana unitária para todos.

Os apontamentos aqui delineados são de que novos olhares sejam direcionados à reestruturação do Ensino Médio e à formação do aluno, acreditando numa educação que contemple o desenvolvimento humano, tendo no sistema educacional brasileiro a agregação na matriz curricular, os conhecimentos já existentes construídos historicamente pela humanidade e não suprimir ou secundarizar alguns deles. Nesse sentido, as políticas voltadas para o ensino médio brasileiro devem proporcionar o êxito do aluno como autor de uma aprendizagem significativa e concreta neste mundo contemporâneo cheio de desafios

\section{6.-Refêrencias.}

Catania, A.C. (1999). Aprendizagem: comportamento, linguagem e cognição. Porto Alegre: Artmed.

Fernandez, A. (2001). O saber em jogo: a psicopedagogia propiciando autorias de pensamento. Porto Alegre: Artmed.

Freire, L.G.L. (2006). Concepções e abordagens sobre a aprendizagem: a construção do conhecimento através da experiência do aluno. Ciências \& Cognição. Vol. 09 .

Gil, A.C. (2010). Como elaborar projetos de pesquisa. São Paulo: Atlas.

Lakatos, E.M., Marconi, M.A. (2010). Fundamentos de metodologia científica. São Paulo: Atlas. 
M.E. (1999). Parâmetros Curriculares Nacionais do Ensino Médio. Brasília: Ministério da Educação.

M.E. (2009). Ministério da Educação: Secretaria de Educação Básica. Ensino Médio Inovador. Brasília: Ministério da Educação.

MEC. (2017). Novo Ensino Médio. Disponível em: <http://portal.mec.gov.br. Acesso em: 14 jul.2019. Brasília: Ministério da Educação.

Moreira, M.A. (2003). Linguagem e Aprendizagem significativa. Aprendizagem significativa. Belo Horizonte: Vozes.

PNE (2014). Plano Nacional de Educação Plano Nacional de Educação: Lei n.13.005, de 25 de junho de 2014, que aprova o Plano Nacional de Educação (PNE) e dá outras providências. Brasília: Câmara dos Deputados.

Tardif, M. (2002). Saberes docentes e formação profissional. Rio de Janeiro: Vozes. 